\title{
USING THE EXPECTANCY VALUE MODEL OF MOTIVATION TO UNDERSTAND THE RELATIONSHIP BETWEEN STUDENT ATTITUDES AND ACHIEVEMENT IN STATISTICS
}

\author{
MICHELLE HOOD \\ Griffith Health Institute, Griffith University, Australia \\ michelle.hood@griffith.edu.au \\ PETER A. CREED \\ Griffith Health Institute, Griffith University, Australia \\ p.creed@griffith.edu.au \\ DAVID L. NEUMANN \\ Griffith Health Institute, Griffith University, Australia \\ d.neumann@griffith.edu.au
}

\begin{abstract}
We tested a model of the relationship between attitudes toward statistics and achievement based on Eccles' Expectancy Value Model (1983). Participants ( $n=149 ; 83 \%$ female) were second-year Australian university students in a psychology statistics course (mean age $=23.36$ years, $S D=$ 7.94 years). We obtained demographic details, past performance, attitudes, and expectancies in Week 2, and attendance records (effort) and course marks (achievement) at the end of semester. Path analysis was conducted via AMOS 19. The final model fit well and explained $40 \%$ of the variance in achievement. Past performance (22\%), effort (8\%), and expectancies (2\%) made significant direct contributions. There were significant indirect contributions by each attitude component. Cognitive competence made the largest indirect contribution.
\end{abstract}

Keywords: Statistics education research; Statistics attitudes; Statistics achievement

\section{INTRODUCTION}

University students often hold negative attitudes regarding mathematics and science courses, including statistics courses, which many face as a compulsory part of their degree (Mallow et al., 2010). Negative attitudes toward statistics influence student learning and adoption of statistical thinking, student achievement in these courses, and the likelihood that students will apply their statistical knowledge outside of the classroom, including in their professional lives (Gal, Ginsburg, \& Schau, 1997; Schau, 2003b). Therefore, understanding these attitudes and their relationship with learning and achievement is important to developing teaching approaches that foster positive attitudes, better achievement, and a life-long embrace of statistical thinking.

Various theoretical frameworks have been used to explain the relationship between a range of attitudes toward statistics (including efficacy, perceived difficulty, affect, expectancy, value, and effort) and achievement. These include Bandura's (1997) social-cognitive learning theory (Finney \& Schraw, 2003), Onwuegbuzie, Bailey, and Daley's (2002) anxiety-expectation mediation model (Onwuegbuzie, Slate, Paterson, Watson, \& Schwartz, 2000; Onwuegbuzie \& Wilson, 2003), Gardner's (1985) socio-educational model of second language learning adapted to statistics achievement (Lalonde \& Gardner, 1993; Tremblay, Gardner, \& Heipel, 2000), Dweck's (1986) achievement goal theory (Bandalos, Finney, \& Geske, 2003), attributional and learned helplessness theories (Budé et al., 2007), and Eccles' (2005; Eccles et al., 1983) expectancy value model of achievement motivation (EVM; Ramirez, Emmioğlu, \& Schau, 2010; Sorge \& Schau, 2002). These approaches vary also in their breadth of focus on attitudes. For example, using Bandura's social-

Statistics Education Research Journal, 11(2), 72-85, http://www.stat.auckland.ac.nz/serj

C International Association for Statistical Education (IASE/ISI), November, 2012 
cognitive learning approach, Finney and Schraw only examined the role of efficacy attitudes. On the other hand, Eccles' EVM encompasses a broad range of attitudes, including efficacy, affective reactions, values, expectancies of success, perceptions of difficulty, and effort. We use the EVM to test a comprehensive range of antecedent variables to students' achievement in an advanced statistics course.

\subsection{ECCLES’ EXPECTANCY VALUE MODEL}

This model was originally developed to explain gender differences in mathematics engagement and achievement in schoolchildren (Eccles et al., 1983). Subsequently, it has been used to explain how expectancies and values directly and indirectly influence achievement choices, performance, effort, and persistence across a wide range of academic and physical domains and age groups (Wigfield \& Cambria, 2010; Wigfield \& Eccles, 2000). In this model, expectancies for success and subjective task values are reciprocally related to each other and directly related to achievement-related choices and performance (Wigfield \& Cambria). Expectancies focus on future success and, as such, are distinct from, although related to, ability beliefs, which focus on present ability (Wigfield \& Eccles, 2002). Subjective task values refer to the "quality of the task that contributes to the increasing or decreasing probability that an individual will select it" (Eccles, 2005, p. 109). Tasks that are perceived as valuable are more likely to be associated with a wide range of motivational outcomes, including better achievement (Shechter, Durik, Miyamoto, \& Harackiewicz, 2011). Subjective task values have several components (Wigfield, 1994). Interest or intrinsic value refers to the enjoyment one gains from engaging in the task. Attainment value refers to the importance placed on doing well at that task. Utility value refers to how useful the task is to a person's future (e.g., undertaking a statistics course in order to become a psychologist). Finally, relative cost, which has been least studied (Wigfield \& Cambria), refers to assessments of how much effort is needed to accomplish the task and the cost of that in terms of other activities (e.g., losing time to socialize). Expectancies and values are influenced by the individual's goals and general self-schema (short- and long-term goals, self-concept and ability beliefs, and perceptions of task difficulty). Values are also influenced by the individual's affective reactions. More distally, past performance and aptitude, as well as the socializer's expectations and behaviors, influence these goals, self-schema, and affective reactions.

Although several instruments have been developed to measure attitudes toward statistics (e.g., Roberts \& Saxe, 1982; Wise, 1985), the Survey of Attitudes Toward Statistics (SATS-28 and SATS36; Schau 1992, 2003a, respectively; Schau, Stevens, Dauphinee, \& Del Vecchio, 1995) is most congruent with testing Eccles' EVM (Ramirez et al., 2010). The 28-item version (SATS-28) assesses four components of attitudes (affect, cognitive competence, value, and difficulty); whereas the 36item version (SATS-36) also assesses interest and effort. Ramirez et al. argued that there is congruence between (a) affect and EVM affective reactions and enjoyment value, (b) cognitive competence and EVM abilities self-concept and expectancies, (c) value and EVM attainment and utility value, (d) difficulty and EVM perception of task demands, (e) interest and EVM interest value, and (f) effort and EVM relative cost. Though studies have shown that scores from the SATS-28 often are related to statistics achievement (e.g., Chiesi \& Primi, 2010; Nasser, 2004), most have done so in the absence of a theoretical framework and have not examined the relationships between individual attitude components and achievement. Sorge and Schau (2002) used the SATS-28 in conjunction with the EVM to predict statistics achievement in undergraduate engineering students. They demonstrated the utility of applying this model to understanding statistics achievement, finding that student perceptions of their mathematical ability, self-reported performance in high school mathematics, selfreported tertiary grade point average and affect were directly related to achievement. There were also indirect paths from difficulty via cognitive competence to affect, and thereby, achievement. Perceived difficulty and affect were related to value, but, contrary to the EVM, value was not related to achievement.

\subsection{THE CURRENT STUDY}

This study extended Sorge and Schau's (2002) use of the EVM and SATS-28 to explain statistics achievement by incorporating measures of effort and expectancies to test a more complete model. We 
used psychology students who face compulsory statistics courses as part of their degree and who commonly report negative attitudes regarding this (Tremblay et al., 2000). Psychology students are less likely than are engineering students to have a strong mathematical background, which is predictive of better attitudes and achievement. In fact, Mulhern and Wylie (2004) found that numeracy skills and mathematics backgrounds of psychology students in the UK have fallen significantly over the last few decades. They gave cohorts of students in 1992 and 2002 the same tests of mathematical thinking relevant to understanding statistics in psychology that Greer and Semrau had used in 1984 (cited in Mulhern \& Wylie). The percentage of students correctly answering the same probability and sampling test question fell from $30 \%$ in 1984 to $28 \%$ in 1992 and $11 \%$ in 2002 . Similar trends were seen on other test items (e.g., calculation: $47 \%, 33 \%$, and $15 \%$, respectively). From 1992 to 2002, the percentage of students entering psychology programs with A-level math fell from $18 \%$ to $9 \%$. This lower level of mathematical knowledge results in students feeling overwhelmed by the content of statistics courses. Unlike engineering students who are likely to expect statistics and mathematics courses in their degree and see its relevance to their profession, $40 \%$ of psychology students do not realize that their degree includes statistics when they enroll (Ruggeri, Diaz, Kelley, \& Papousek, 2008), and they often fail to see the relevance to their future professional needs. However, the training in research methods and statistics that psychology students receive is credited with developing their ability to apply critical thinking skills to real life problems, a necessary skill for professional psychologists (VanderStoep \& Shaughnessy, 1997).

Psychology students generally face more than one compulsory statistics course in their degree, often having to complete one such course at each year level (About.com Psychology, 2012). We tested the EVM using students enrolled in a compulsory second-year statistics and research methods course. Most of the existing work has examined attitudes and achievement in students undertaking introductory statistics courses (even those done with graduate students generally involve introductory statistics courses, e.g., Onwuegbuzie et al., 2000). Gal and Ginsburg (1994) argued that the fundamental problem with asking students at the start of their first statistics course about their attitudes toward statistics is that they do not necessarily know what "statistics" means, and consequently those attitudes are more likely to be based on attitudes to, or past experiences with, mathematics, or on hearsay. Studies have confirmed that prior mathematics knowledge and achievement predict negative feelings about statistics (affect) although not attitudes regarding its worth (value) in beginning college students (Carmona, Martinez, \& Sanchez, 2005; Schutz, Drogosz, White, \& Distefano, 1998). Another issue is that when samples are drawn from introductory statistics courses, past performance, an important component of the EVM, is operationalized as high school mathematics performance, current mathematics ability, or current grade point average (e.g., Chiesi \& Primi, 2010; Sorge \& Schau, 2002). By examining attitudes and achievement in advanced statistics courses, it is possible to use past statistics performance as the predictor. Thus, it is a better test of the EVM model to examine these relationships after students have some understanding of what statistics is and when prior experience in statistics can be used as a predictor.

Figure 1 shows the model we tested. This was based on Eccles' EVM, although we did not include the more distal aspects of the EVM, such as cultural milieu and individual perceptions (e.g., of gender stereotypes) and interpretations (e.g., locus of control). Our model was also based on the findings of previous empirical studies using the EVM, especially those of Sorge and Schau (2002). We operationalized EVM goals and general schema as perceived task demands (difficulty) and selfconcept of ability (cognitive competence), and operationalized subjective task values as value (attainment and utility values) and relative cost (effort). Difficulty, cognitive competence, and value were measured using the SATS-28. Effort was measured directly by recording student attendance at tutorial classes. EVM affective reactions were operationalized as the SATS-28 affect. EVM expectancies of success were assessed using items generated for this study, which referred to students' expectations that their performance would result in success in the course, using Atkinson's (1957) and Bandura's (1977) definitions on which this aspect of the EVM was based. Past performance was the grade obtained in the prerequisite research methods and statistics course. The outcome, achievement, was the final percentage score in the course, based on a weighted composite of the mid-semester exam, written assignment, and final exam. In the EVM (see Wigfield \& Cambria, 2010), past performance is only directly related to affective reactions (affect) and indirectly to the goals and general schema (difficulty and cognitive competence) via individual interpretations of their 
experience. It is not related directly to achievement. However, Sorge and Schau (2002) found that previous success was directly related to cognitive competence (although not difficulty), as well as to achievement. Therefore, we included these direct paths in our hypothesized model.

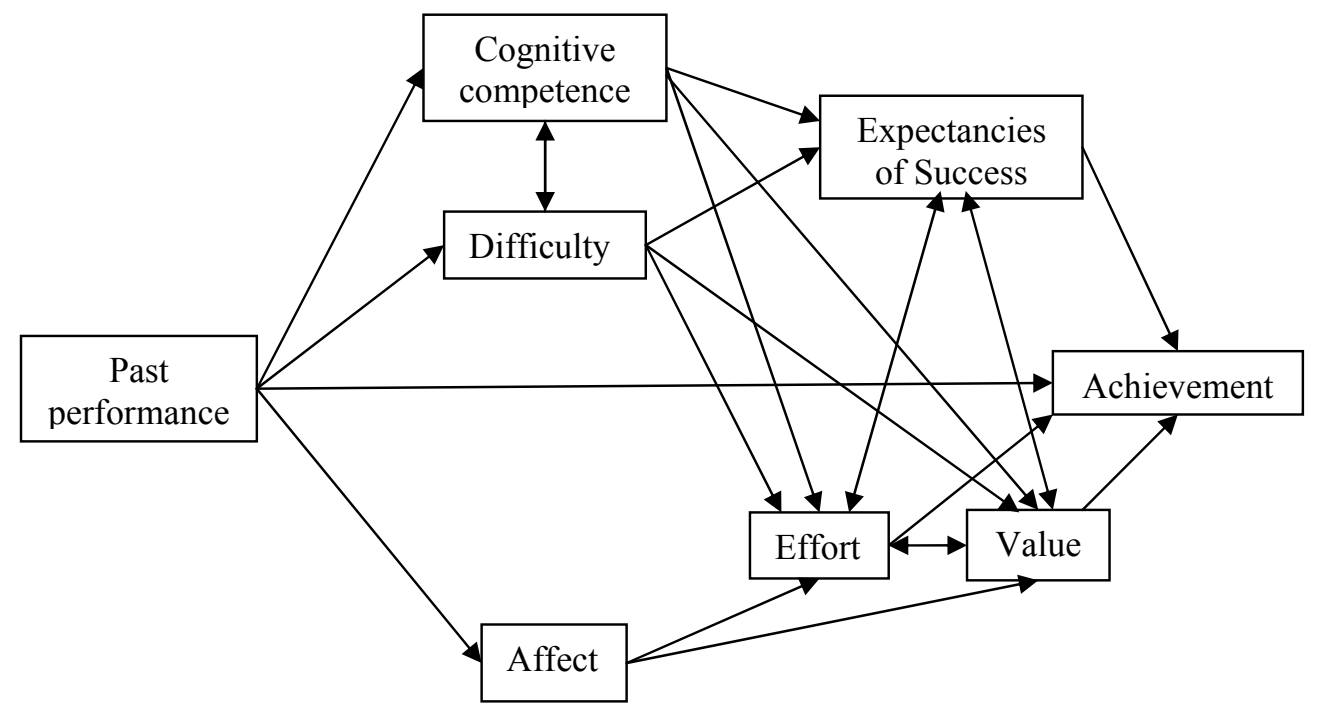

Figure 1. Hypothesized model of the relationships among past performance, student attitudes, and statistics achievement

\subsection{PARTICIPANTS}

\section{METHOD}

Participants were students enrolled in a compulsory second-year psychology research methods and statistics course at a large, multi-campus, urban university in Queensland, Australia. Of those who originally consented to participate in the study $(n=163), 149(83 \%$ female) completed the course and had a score on the outcome variable, achievement. This represented $93 \%$ of those who completed the course. The mean age was 23.36 years ( $\mathrm{SD}=7.94$ years, ranging from 18 to 65 years). Most participants had English as their main language (89\%), which is consistent with the general population of students at the participating university. Most (79\%) were enrolled in a single psychology degree, with the remainder enrolled in double degrees in psychology with law, exercise science, business, or education. The majority of participants were undertaking this course for the first time; however, $10 \%$ were repeating the course (approximately half due to prior failure and half to improve a previous pass grade). The repeating students did not differ from non-repeating students on any measures.

\subsection{MEASURES AND PROCEDURE}

The research ethics committee at the participating university granted ethical approval. All students who were enrolled in the course and who attended the first tutorial class were invited to participate. Volunteers completed a pen-and-paper questionnaire during that class under the supervision of the course tutors. The tutors were briefed on administration of the questionnaire but were not involved in the study and were unaware of the research questions. The questionnaire items assessed demographic details and attitudes, and requested permission to access data on the student's attendance at tutorial classes (effort) and their assessment marks (achievement). Demographic details were age, gender, main language, degree, whether they were repeating the course, and their grade (Fail $=2$, Pass conceded, Pass, Credit, Distinction, or High Distinction =7) in the prerequisite research methods and statistics course (past performance). Effort was the number of tutorial classes attended during the semester $(\max =11)$. Achievement was the overall percentage obtained in the course. 
Four attitude components (affect, cognitive competence, difficulty, and value) were measured using the SATS-28 (Schau, 1999). Pre- and post-versions of the survey are available. We used the post-version because students had just completed an introductory research methods and statistics course, so that wording (e.g., "I like statistics") was more relevant than that in the pre-version (e.g., "I will like statistics"), even though we administered the survey at the start of this particular course. Affect assessed students' positive and negative feelings concerning statistics (6 items: e.g., "I like statistics," "I am scared by statistics"). Cognitive competence measured attitudes about intellectual knowledge and skills applied to statistics (6 items: e.g., "I can learn statistics"). Value measured student attitudes regarding the usefulness, relevance, and worth of statistics (9 items: e.g., "Statistics is worthless"). Difficulty assessed attitudes regarding statistics being difficult or easy (7 items: e.g., "Statistics formulas are easy to understand"). Students indicated their agreement with each statement using a 7-point Likert-type scale with anchors of $1=$ Strongly Disagree and $7=$ Strongly Agree. Items indicating negative attitudes were reverse scored so that higher score represented positive attitudes. Average scores for each component were formed by adding the scores on all items and dividing by the total number of items for that component. Schau (1999) reported acceptable internal reliabilities, ranging from .64 to .77 for difficulty, .77 to .83 for cognitive competence, .80 to .85 for value, and .81 to .84 for affect. The current sample yielded Cronbach's alphas for these subscales of .78, .88, .86, and .85 , respectively. Validity of the 4 -factor structure has been demonstrated (Schau et al., 1995; Sorge \& Schau, 2002).

Expectancies of success were measured using three items developed for the study. The items were based on Atkinson's (1957) definition of expectancies as anticipations that their performance would lead to success (or failure) as well as Bandura's (1977) definition of efficacy expectancies as beliefs that the individual can produce the desired outcome, on which Eccles et al. (1983) based the EVM concept (Wigfield, 1994; Wigfield \& Cambria, 2010). Our items were, "If I put the effort in, I will understand research methods and statistics," "I expect to do well in this research methods and statistics course," and "The time I spend working on the material and exercises in this course will be worth it." Participants rated their expectancies using the same 7-point response scale as the SATS-28. An exploratory factor analysis using the principal components method of extraction showed that these items loaded on one component with loadings of $.86, .78$, and .74 , respectively. This component explained $63 \%$ of the variance in these items. Cronbach's alpha was .69 .

\subsection{DESCRIPTION OF THE COURSE}

The course in which this study was conducted is the second in a sequence of four such compulsory courses within the degree. Average enrollment is around 180 at the start of semester with around 160 completing the semester. This represents a typical dropout rate for psychology courses in general at this university. Students are taught experimental design, including measurement and manipulation of variables, reliability, and validity; as well as experimental data analysis techniques from the Analysis of Variance (ANOVA) family, including between and within subjects $t$-tests, oneway ANOVA, and factorial ANOVA. The course is taught over a 13-week semester via weekly 2hour lectures and 1-hour small-group tutorial classes (tutorials commence week 2). In the tutorials, students work on identifying variables, hypotheses, and methodological strengths and weaknesses in research examples, and are taught to conduct analyses using the SPSS statistical package. There are three assessment items: a mid-semester exam, a written assignment, and a final exam. For the assignment, students participate in an experiment to generate data, which they then analyze using SPSS to test given hypotheses and write up in a lab report format using American Psychological Association (2001) style.

\section{RESULTS}

\subsection{PRELIMINARY ANALYSES}

There was a small amount of missing data ( $2 \%$ missing values). Little's test indicated that these data were missing completely at random, $\chi^{2}(3, n=149)=1.17, p=.76$. Thus, it was permissible to replace the missing values, which was done using the data imputation method in AMOS 19. 
Descriptive statistics for the predictor and outcome measures are reported in Table 1. Mardia's test for multivariate normality indicated slight non-normality (critical ratio, c.r. $=2.34, p<.05$ ). Univariate skewness and kurtosis statistics were examined. There was significant negative skew for effort (c.r. $=-4.31)$, value (c.r. $=-2.64)$, and expectancies $($ c.r. $=-2.28)$. There were no problems with kurtosis. Consequently, we used the recommended solution for analyzing non-normal data of bootstrapping (Blunch, 2008).

Table 1. Descriptive statistics and bivariate correlations between predictors and outcome measure

\begin{tabular}{|c|c|c|c|c|c|c|c|c|c|}
\hline Variable & Mean $(95 \% \mathrm{CI})$ & 1. & 2. & 3. & 4. & 5. & 6. & 7. & 8. \\
\hline 1. Past perform. & $4.77(4.62,4.91)$ & -- & & & & & & & \\
\hline 2. Difficulty & $3.05(2.91,3.20)$ & .14 & -- & & & & & & \\
\hline 3. Affect & $3.73(3.53,3.93)$ & $.29 * *$ & $.70 * *$ & -- & & & & & \\
\hline 4. Cog. comp. & $4.46(4.26,4.65)$ & $.38 * *$ & $.65 * *$ & $.78 * *$ & -- & & & & \\
\hline 5. Value & $4.95(4.78,5.12)$ & $.23 *$ & $.24 *$ & $.33 * *$ & $.37 * *$ & -- & & & \\
\hline 6. Expectancies & $5.78(5.63,5.93)$ & $.27 *$ & $.33 * *$ & $.49 * *$ & $.59 * *$ & $.49 * *$ & -- & & \\
\hline 7. Effort & $8.71(8.35,9.07)$ & $.22 *$ & -.11 & -.08 & .00 & -.02 & .00 & -- & \\
\hline 8. Achieve (\%) & $63.36(60.71,66.01)$ & $.57 * *$ & .09 & .11 & $.28 *$ & $.23 *$ & $.28 *$ & $.38 * *$ & -- \\
\hline
\end{tabular}

The mean grade for past performance was in the pass range, with grades ranging from fail to high distinction. Scores on the attitude scales indicated that, on average, students somewhat agreed that statistics was difficult and they felt slightly negatively toward it. However, on average, they also somewhat agreed that they felt competent and saw the value of statistics to their profession and lives.

Table 1 also shows the bivariate correlations between predictor and outcome measures. All predictors except difficulty and affect were significantly correlated with achievement, with past performance showing the strongest correlation $\left(r^{2}=32 \%\right)$. Effort showed a moderate correlation, explaining $14 \%$ of the variance, whereas cognitive competence, value, and expectancies all showed weak correlations, explaining 5 to $8 \%$ of the variance. Past performance showed weak to moderate correlations with all attitude components except difficulty. There were strong correlations among difficulty, affect, and cognitive competence $\left(r^{2}=42-61 \%\right)$, and each of these attitude components was correlated with expectancies and value. As expected from the EVM, expectancies and value were correlated $\left(r^{2}=24 \%\right)$.

\subsection{PATH ANALYSIS}

Path analysis (structural equation modelling using observed variables; Loehlin, 1998) was conducted via AMOS 19 to test the hypothesized model (Figure 1). We performed 1000 bootstrapped replications. The bootstrapping approach yielded estimates of direct and indirect effects in the model. We used the bias corrected approach to estimate standard errors, $p$-values, and confidence intervals. All 1000 bootstrap samples converged and yielded meaningful solutions. The Bollen-Stine bootstrap $p$-value was used to test overall model fit in place of the traditional $\chi^{2}$ statistic (Blunch, 2008). Model fit was also assessed using the Comparative Fit Index (CFI), which compares the specified model to a model with complete independence, and the Root Mean Square Error of Approximation (RMSEA), which estimates the error due to the approximate fit of the model. Good model fit is indicated by nonsignificant Bollen-Stine $p$-value, CFI values above .90 to .95 , and RMSEA values less than .05 to .08 (Blunch).

The hypothesized model (Figure 1) did not show a satisfactory fit to the data, $\chi^{2}(11, n=149)=$ 252.62, Bollen-Stine $p$-value $=.001, \mathrm{CFI}=.47$, RMSEA $=.39$. Non-significant paths in the model were pruned. Modification indices indicated that the addition of non-hypothesized paths from difficulty to affect, affect to cognitive competence, and past performance to effort would improve the model fit. These paths made sense based on past research and theory. Interrelationships between difficulty, cognitive competence, and affect have been found previously (Cashin \& Elmore, 2005; Gal et al., 1997; Vanhoof, Kuppens, Sotos, Verschaffel, \& Onghena, 2011). According to motivation 
theories, students who believe they can and will do well, for example, because they performed well in the past, expend more effort (Pintrich \& Schunk, 2002). Thus, these paths were included. As a result, the final model showed good fit, $\chi^{2}(16, n=149)=19.08$, Bollen-Stine $p$-value $=.32$, CFI $=.99$, RMSEA $=.04$. Figure 2 shows all of the paths and corresponding coefficients that were significant in this final model.

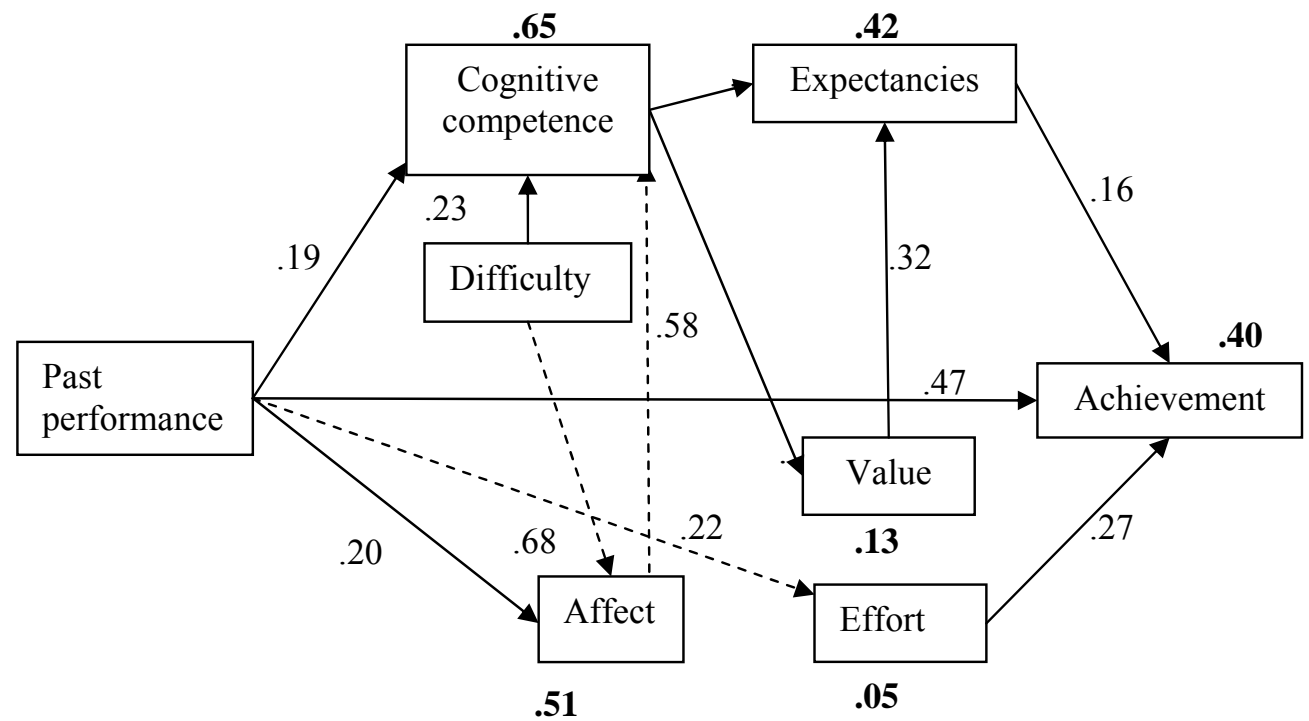

Figure 2. Final model of the relationship between student attitudes and statistics achievement. Dashed lines indicated added paths. Significant standardized path coefficients are indicated in normal font. Squared multiple correlation coefficients are shown in bold.

Overall, $40 \%$ of the variance in achievement was explained by this model. All attitude components were either directly or indirectly related to statistics achievement. As hypothesized, past performance, effort, and expectancies each made significant direct contributions to achievement. However, value did not. Past performance made the largest direct contribution, accounting for around half of the explained variance in achievement (22\%). It also made small but significant indirect contributions to achievement via effort, via a path through cognitive competence and expectancies, and via a path through affect, cognitive competence, and expectancies (total $<1 \%$ of the variance indirectly explained). Thus, previously performing better in research methods and statistics was related to expending more effort currently, to having more positive feelings about statistics, and to feeling more competent regarding statistics and via that to having higher expectancies for future success. This translated to better achievement. Effort directly explained $8 \%$ of the variance in achievement while expectancies directly explained $2 \%$ of this variance. Value was only weakly, indirectly related to achievement via its relationship with expectancies $(<1 \%$ variance explained). Thus, valuing statistics more was related to holding higher expectancies for success, which was related to higher achievement.

There were several other weak, albeit significant, indirect relationships with achievement, each of which explained less than $1 \%$ of the variance. Table 2 summarizes all of the direct, indirect, and total effects.

\section{DISCUSSION}

Ramirez et al. (2010) argued that the SATS provides an ideal measure for assessing an expectancy-value model of achievement in statistics. However, to date, we are only aware of one study (Sorge \& Schau, 2002) that has empirically tested this. We extended that work by testing a broader model of the relationship between statistics attitudes and achievement. Although the hypothesized model based on the EVM and the findings of Sorge and Schau (2002) was not supported, our final model did show good fit and is in keeping with many elements of the EVM in 
Table 2. Direct and indirect effects in the final model

\begin{tabular}{|c|c|c|c|c|c|c|c|c|}
\hline Variable & Effect & $\begin{array}{l}\text { Past } \\
\text { perform }\end{array}$ & Difficulty & Affect & Cog Comp & Value & Expect & Effort \\
\hline \multirow[t]{3}{*}{ Affect } & Direct & $.20 * *$ & $.69 * *$ & & & & & \\
\hline & Indirect & & & & & & & \\
\hline & Total & $.20 * *$ & $.69 * *$ & & & & & \\
\hline \multirow[t]{3}{*}{ Cog Comp } & Direct & $.19 * *$ & $.23 * *$ & $.58 * *$ & & & & \\
\hline & Indirect & $.11 * *$ & $.40 * *$ & & & & & \\
\hline & Total & $.30 * *$ & $.62 * *$ & $.58 * *$ & & & & \\
\hline \multirow[t]{3}{*}{ Value } & Direct & & & & $.36 * *$ & & & \\
\hline & Indirect & $.11 * * *$ & $.23 * * *$ & $.21 * * *$ & & & & \\
\hline & Total & $.11 * * *$ & $.23 * * *$ & $.21 * * *$ & $.36^{* *}$ & & & \\
\hline \multirow[t]{4}{*}{ Expect } & Direct & & & & $.46^{* *}$ & & & \\
\hline & & & & & & $32 * *$ & & \\
\hline & Indirect & $.17 * * *$ & $.36 * *$ & $.33 * * *$ & $.12 * * *$ & & & \\
\hline & Total & $.17 * * *$ & $.36 * *$ & $.33 * * *$ & $.58 * *$ & $.32 * *$ & & \\
\hline \multirow[t]{4}{*}{ Effort } & Direct & .22 & & & & & & \\
\hline & & $* *$ & & & & & & \\
\hline & Indirect & & & & & & & \\
\hline & Total & $.22 * *$ & & & & & & \\
\hline \multirow[t]{4}{*}{ Achieve } & Direct & .47 & & & & & $.16^{*}$ & $.28 * *$ \\
\hline & & $* * *$ & & & & & & \\
\hline & Indirect & $.09 *$ & $.06^{*}$ & $.05 *$ & $.09 *$ & $.05^{*}$ & & \\
\hline & Total & $.55 * *$ & $.06^{*}$ & $.05 *$ & $.09 *$ & $.05^{*}$ & $.16^{*}$ & $.28 * *$ \\
\hline
\end{tabular}

explaining statistics achievement in undergraduate psychology students. Despite the fact that we included more predictors from the EVM in our model (effort and expectancies) than Sorge and Schau did, our final models were quite consistent. However, both our results and those of Sorge and Schau show that some elements of the EVM are not supported in predicting statistics achievement in tertiary students. Further, additional paths not hypothesized in the EVM, but considered meaningful, were supported in our model.

We were able to explain $40 \%$ of the variance in achievement. The most important predictor was past statistics performance. This result is consistent with Sorge and Schau (2002), although they used self-reports of perceived mathematics ability, high school mathematics performance, and current university grade point average, whereas we used grade in a prerequisite first-year statistics course. These results are also consistent with other studies that have operationalized past performance as high school mathematics performance and found it to be the strongest predictor of statistics achievement in introductory statistics courses (Chiesi \& Primi, 2010; Nasser, 2004; Tremblay et al., 2000). Thus, stronger foundational skills, either in high school mathematics for introductory statistics courses or in prerequisite introductory statistics courses for more advanced courses, are related directly to better achievement.

This finding is not consistent with the EVM in which past performance is only indirectly related to achievement via the person's affective reactions to that past performance and their interpretations of that performance, which, in turn, are related to their goals and general self-schema. We did not include a measure of interpretations but past performance was related to affect as well as to one aspect of general self-schema, cognitive competence, but not to the other, difficulty. Students who previously performed well in statistics showed more positive feelings about and attitudes regarding their competence for the current course. An attitude of competence was associated, in turn, with higher expectancies for success and value, consistent with the EVM. However, contrary to the EVM in which affective reactions are related to subjective task values, in our model, affect was not directly associated with our measures of subjective tasks values, value or effort, although it was indirectly associated with value via cognitive competence. Thus, feeling more positive about statistics was associated with feeling more competent and via that with expecting to succeed in statistics and valuing it more. These results also differ a little from Sorge and Schau (2002). Like us, they found 
past performance was directly related to cognitive competence, but, in contrast, they only found past performance was indirectly related to affect via cognitive competence, a finding also not consistent with the EVM.

Higher past performance was associated with greater effort, and, via that, with achievement. Effort was conceptualized as a measure of the EVM subjective task value of relative cost. Relative cost has rarely been examined (Wigfield \& Cambria, 2010) and, to our knowledge, never in relation to achievement. In fact, few studies of statistics achievement have even included effort. We measured effort by direct observation of class attendance. Most previous studies measured self-reported intentions or self-reported actual effort, as does the effort subscale of the SATS-36. Tremblay et al. (2000) found that self-reported effort in studying for a statistics course predicted achievement. However, Budé et al. (2007) found that significant bivariate associations between self-reported effort and achievement became non-significant once other factors, notably persistence, were entered into the model. Thus, results may vary depending on other factors included in the model.

It should be noted that we did not capture other aspects of effort, such as completing homework assignments, studying, or attending lectures, and did not assess students' cost-benefits decision making, which might be an important aspect of relative cost. We made the assumption that greater tutorial attendance represented the outcome of a costs-benefit decision to prioritize expending effort on this course over other potentially competing activities (including doing nothing). To our knowledge, only one measure exists that specifically assesses the relative cost of tertiary study vis-àvis competing life demands (Battle \& Wigfield, 2003). Understanding the decision making that leads to students expending effort attending classes and studying for statistics at the expense of other activities remains an important task for future research. Therefore, it is recommended that future research should incorporate a measure that better assesses relative cost. This has the potential to differentiate the motivational components that underlie observable effort. It is also possible that our measure of effort as tutorial attendance assesses aspects of teaching efficacy, and that this explains at least part of the relationship with achievement. However, the results of Tremblay et al. (2000) in which effort was measured as (self-reported) independent study, showed that, independent of teaching efficacy, effort is predictive of statistics achievement.

Although we found that effort predicted achievement, we did not find the expected relationship between our other measure of subjective task values, value, and achievement. Value and achievement were significantly correlated, but not directly related when other factors were included in the model. Others have also failed to find a path from value to achievement in statistics and mathematics (Bong, 2001; Pajares \& Miller, 1994; Sorge \& Schau, 2002; Tremblay et al., 2000). Thus, this seems to be a robust finding and not a function of the particular sample or specific domain of interest.

There are several possibilities for our failure to find a relationship between value and achievement, which is not expected based on the EVM. When students are compelled to undertake statistics (or mathematics) courses, as was the case in these studies, the extent to which they value statistics might not be important to their achievement. Possibly, they recognize that these courses are valuable in reaching their long-term goals of a particular professional qualification. That aspect of value to long-term goals might be more predictive of achievement than how much they value statistics per se. Future studies should also include measures of short- and long-term goals, as conceptualized in the EVM, to clarify this. Valuing statistics might be more important to achievement when students choose to undertake these typically disliked courses. Consistent with this, Bong (2001) found that though value did not predict current achievement it did predict intentions to enroll in additional statistics courses beyond the current compulsory course. This aspect of the EVM needs to be tested with a sample drawn from non-compulsory statistics courses. However, understanding the attitudes and predictors of achievement in compulsory statistics courses remains an important focus given that many university degrees include these courses as core components.

Another possible reason why we, and Sorge and Schau (2002), failed to find a relationship between value and achievement might stem from the measure of value. The SATS value subscale mainly focuses on the utility value (e.g., "I use statistics in my everyday life") within the EVM subjective task values (although according to Ramirez et al., 2010, it is also congruent with the attainment task value). It may be important to more comprehensively assess attainment/importance value as a distinct construct. Attainment value, which refers to the importance of doing well on a given task (Eccles et al., 1983), may be more relevant to achievement in a specific course than the 
broader utility value, which refers to how a task fits into one's future plans (Eccles et al.). The other subjective task values in the EVM are relative cost, which we operationalized as effort and found predicted achievement, and intrinsic or interest/enjoyment value. Ramirez et al. argued that the SATS affect is congruent with both the enjoyment value (e.g., "I enjoy taking statistics courses") and affective reactions. In our model, we conceptualized affect as a measure of affective reactions, not enjoyment value, and, as expected from the EVM, did not find a direct path from it to achievement. However, others (Budé et al., 2007; Sorge \& Schau, 2002) found that affect predicted achievement, although those models did not include effort or expectancies (and Budé et al.'s model was not based on the EVM). Further work utilizing distinct measures of affective reactions versus interest/enjoyment value is needed to clarify their roles in predicting statistics achievement. The SATS-36 interest subscale provides a useful measure of that aspect of subjective task values.

In our model, the expected reciprocal paths between effort and value were not supported nor were the expected reciprocal paths between these and expectancies. Only the path from value to expectancies was supported. Thus, valuing statistics leads to expectancies of success, and from there to achievement, but expecting to succeed does not lead to valuing statistics. Effort is not predictive of expecting to succeed nor does expecting to succeed predict effort. Similarly, effort and value were unrelated. There are a couple of possible explanations for these unexpected findings, which are not consistent with the EVM. It is possible that these findings arise from our measure of effort. Using a measure that is better aligned with relative cost might result in some of these hypothesized paths being supported. Second, these results may arise from the compulsory and anxiety-provoking nature of the course. In a less threatening course and one that is voluntarily taken, the expected paths between value and effort and between these and expectancies may be supported. However, when compelled to do a course that many find challenging, the expected relationships between value, effort, and expectancies of success may break down. For many students in that situation, effort may not be an outcome of value (nor value of effort) but rather a result of necessity, and regardless of how much effort they put in, they may not expect to succeed because they lack confidence.

Consistent with the EVM, expectancy and effort were directly related to achievement, although contrary to the EVM, value was only indirectly related to achievement via expectancies. Most existing studies of statistics achievement have not included expectancies for success but only measures of current ability beliefs, such as self-efficacy or cognitive competence, which predict achievement (e.g., Bong, 2001; Finney \& Schraw, 2003). However, as Wigfield and Eccles (2002) explained, expectancies focus on future success whereas ability beliefs focus on present ability, and, as such, form part of the general self-schema that predict expectancies of success. Consistent with this, in our model, cognitive competence (current ability belief) predicted expectancies (future success) and, thereby, achievement. We also found that cognitive competence predicted value, which is consistent with the EVM.

The current study had some important methodological and design strengths. We tested a broader conceptualization of the EVM than Sorge and Schau (2002), by incorporating effort and expectancies. We also incorporated some objective measures (effort and past performance), rather than relying solely on self-report questionnaires (e.g., Sorge \& Schau). When the participant self-reports all measures, common method error variance can inflate correlations among variables. By obtaining at least some measures via direct observation, we were able to reduce that problem to some extent, although, like most studies of attitudes, there is still a heavy reliance on self-report measures (see Wigfield \& Cambria, 2010). However, as noted already there were some limitations. The SATS-28 affect subscale measures aspects of both affective reactions and enjoyment value. A better distinction between these constructs is needed in future research and using the SATS-36 interest subscale will likely provide that. A better measure of relative cost (e.g., Battle \& Wigfield, 2003) is also needed. Another limitation is that we used the same sample of participants to test and refine the model so these results need replication with a different sample of participants. In addition, a broader model that includes more aspects of the EVM needs to be tested with participants who are forced to take statistics in their degree and those who chose to do so to examine whether there are differences between those populations.

Our results, like those of Sorge and Schau (2002), support some but not all aspects of the EVM. Further, additional paths not included in the EVM resulted in a better model fit. One possibility for these differences is that the EVM, having been mainly developed and tested on mathematics 
achievement in children, does not completely capture the factors relevant to statistics achievement at a tertiary level. The other is that, as we have acknowledged, the SATS-28 and the other measures that we used do not completely match the constructs conceptualized in the EVM, explaining some of our unexpected results. Although the additional paths we included in our final model were not expected based on the EVM, they are meaningful and consistent with previous research and theory.

The EVM proposes a reciprocal relationship between difficulty and cognitive competence. We did not find the expected path from cognitive competence to difficulty, only a direct path from difficulty to cognitive competence. Thus, for undergraduate psychology students studying a core advanced research methods and statistics course, feelings of competence were not predictive of perceptions regarding the difficulty of the course, but perceiving it to be difficult was related to a lower sense of competence to undertake it. However, we also found an indirect path from difficulty to cognitive competence via affect. That is, perceiving statistics to be easier is related to perceiving oneself to be more competent in tackling it both directly and indirectly via feeling more positive towards statistics. Although neither of the paths from difficulty to affect or from affect to cognitive competence was hypothesized, Gal et al. (1997) noted that affect and cognitive competence are strongly related, and difficulty and affect are moderately related. Others have also found that these three attitude components are interrelated (Cashin \& Elmore, 2005; Vanhoof et al., 2011). Whereas Sorge and Schau (2002) found the expected direct relationship between difficulty and cognitive competence, they found an added path from cognitive competence to affect. Thus, in general, these two studies suggest that at least some types of goals and general self-schema are related to affective reactions, something not currently included in the EVM.

In addition, we included a significant path from past performance to effort. According to Pintrich and Schunk (2002), students who believe they can and will do well expend more effort. Therefore, it is possible that students who do well in earlier courses are motivated to put more effort into subsequent courses because they believe they can do well again. It is equally possible that this path reflects a positive relationship between earlier effort, which resulted in better past performance, and higher current effort. Certainly past effort fits into the general category of previous achievementrelated experiences in the EVM, which we specifically operationalized as past performance. Further research using a broader EVM is needed to clarify this.

Despite the differences between our final model and the EVM, our findings do suggest that this model provides a useful starting point for understanding the factors that affect attitudes toward statistics and the way those attitudes influence achievement in tertiary students. Students who believe that learning statistics is easier, who express positive feelings about statistics, and who feel competent about their ability to undertake the course, are likely, in turn, to value statistics more and to express positive future-oriented expectancies for success, which is likely to lead ultimately to better achievement. Consequently, statistics teachers who construct content, teaching approaches, and learning experiences in a manner that reduces the perceived difficulty of statistics, that highlights its value to students' future professional goals, and that increases students' liking for statistics and feelings of competence are likely to ultimately foster better achievement outcomes. Notwithstanding that, foundational knowledge coming into statistics courses is consistently the most important predictor, not only of achievement, but also of many of these attitudes. Therefore, intervening with students who present with poorer foundational skills is likely to not only improve achievement directly but to also do so indirectly by improving many of the important components of their attitudes toward statistics.

\section{ACKNOWLEDGEMENTS}

We would like to thank the course tutors, Michele Dunbar, Kaya Beinke, and Garry Power, who assisted with the data collection for this study.

\section{REFERENCES}

About.com Psychology (2012). Bachelor's degree in psychology.

[Online: http://psychology.about.com/od/education/tp/bachelors-degree-in-psychology.htm] 
American Psychological Association. (2001). Publication manual of the American Psychological Association (5th ed.). Washington, DC: Author.

Atkinson, J. W. (1957). Motivational determinants of risk taking behavior. Psychological Review, 64(6), 359-372.

[Online: http://dx.doi.org/10.1037/h0043445]

Bandalos, D. L., Finney, S. J., \& Geske, J. A. (2003). A model of statistics performance based on achievement goal theory. Journal of Educational Psychology, 95(3), 604-616. [Online: $\mathrm{http}: / / \mathrm{dx}$.doi.org/10.1037/0022-0663.95.3.604]

Bandura, A. (1997). Self-efficacy: The exercise of control. New York: Freeman.

Battle, A., \& Wigfield, A. (2003). College women's value orientations toward family, career, and graduate school. Journal of Vocational Behavior, 62(1), 56-75.

[Online: http://dx.doi.org/10.1016/S0001-8791\%2802\%2900037-4]

Blunch, N. J. (2008). Introduction to structural equation modelling using SPSS and AMOS. London: Sage.

Bong, M. (2001). Role of self-efficacy and task-value in predicting college students' course performance and future enrollment intentions. Contemporary Educational Psychology, 26(4), 553-570.

[Online: http://dx.doi.org/10.1006/ceps.2000.1048]

Budé, L., Van de Wiel, M. W. J., Imbos, T., Candel, M. J. J. M., Broers, N. J., \& Berger, M. P. F. (2007). Students' achievements in a statistics course in relation to motivational aspects and study behaviour. Statistics Education Research Journal, 6(1), 5-21.

[Online: http://www.stat.auckland.ac.nz/ iase/serj/SERJ6\%281\%29 Bude.pdf]

Carmona, J., Martinez, R. J., \& Sanchez, M. (2005). Mathematical background and attitudes toward statistics in a sample of Spanish college students. Psychological Reports, 97(1), 53-62. [Online: http://dx.doi.org/10.2466/pr0.97.1.53-62]

Cashin, S. E., \& Elmore, P. B. (2005). The Survey of Attitudes Toward Statistics scale: A construct validity study. Educational and Psychological Measurement, 65(3), 509-524.

Chiesi, F., \& Primi, C. (2010). Cognitive and non-cognitive factors related to students' statistics achievement. Statistics Education Research Journal, 9(1), 6-26.

[Online: http://www.stat.auckland.ac.nz/ iase/serj/SERJ9\%281\%29 Chiesi Primi.pdf]

Dweck, C. S. (1986). Motivational processes affecting learning. American Psychologist, 41(10), $1040-1048$.

[Online: http://dx.doi.org/10.1037/0003-066X.41.10.1040]

Eccles, J. S. (2005). Subjective task values and the Eccles et al. model of achievement related choices. In A. J. Elliott \& C. S. Dweck (Eds.), Handbook of competence and motivation (pp. 105-121). New York: Guilford.

Eccles (Parsons), J. S., Adler, T. F., Futterman, R., Goff, S. B., Kaczala, C. M., Meece, J. L., \& Midgley, C. (1983). Expectancies, values, and academic behaviors. In J. T. Spence (Ed.), Achievement and achievement motivation (pp. 75-146). San Francisco: W. H. Freeman.

Finney, S. J., \& Schraw, G. (2003). Self-efficacy beliefs in college statistics courses. Contemporary Educational Psychology, 28(2), 161-186.

[Online: http://dx.doi.org/10.1016\%2fS0361-476X\%2802\%2900015-2]

Gal, I., \& Ginsburg, L. (1994). The role of beliefs and attitudes in learning statistics: Towards an assessment framework. Journal of Statistics Education, 2(2).

[Online: www.amstat.org/publications/jse/v2n2/gal.html]

Gal, I., Ginsburg, L., \& Schau, C. (1997). Monitoring attitudes and beliefs in statistics education. In I. Gal \& J. B. Garfield (Eds.), The assessment challenge in statistics education (pp. 37-51). Amsterdam: IOS Press.

[Online: http://www.stat.auckland.ac.nz/ iase/publications/assessbk/chapter04.pdf]

Gardner, R. C. (1985). Social psychological and second language learning: The role of attitudes and motivation. London, UK: Edward Arnold.

Lalonde, R. N., \& Gardner, R. C. (1993). Statistics as a second language? A model for predicting performance in psychology students. Canadian Journal of Behavioral Science, 25(1), 108-125. [Online: $\underline{\text { http://dx.doi.org/10.1037/h0078792] }}$ 
Loehlin, J. C. (1998). Latent variable models: An introduction to factor, path, and structural analysis (3rd ed.). Mahwah, NJ: Lawrence Erlbaum Associates Inc.

Mallow, J., Kastrup, H., Bryant, F. B., Hislop, N., Shefner, R., \& Udo, M. (2010). Science anxiety, science attitudes, and gender: Interviews from a binational study. Journal of Science Education and Technology, 19(4), 356-369.

[Online: http://dx.doi.org/10.1007/s10956-010-9205-z]

Mulhern, G., \& Wylie, J. (2004). Changing levels of numeracy and other core mathematical skills among psychology undergraduates between 1992 and 2002. British Journal of Psychology, 95(3), 355-370.

[Online: http://dx.doi.org/10.1348/0007126041528176]

Nasser, F. M. (2004). Structural model of the effects of cognitive and affective factors on the achievement of Arabic-speaking pre-service teachers in introductory statistics. Journal of Statistics Education, 12(1).

[Online: www.amstat.org/publications/jse/v12n1/nasser.html]

Onwuegbuzie, A. J., Bailey, P., \& Daley, C. E. (2002). The role of foreign language anxiety and students' expectations in foreign language learning. Research in the Schools, 9(1), 33-50.

Onwuegbuzie, A. J., Slate, J. R., Paterson, F. R. A., Watson, M. H., \& Schwartz, R. A. (2000). Factors associated with achievement in educational research courses. Research in the Schools, 7(1), 5365.

Onwuegbuzie, A. J., \& Wilson, V. A. (2003). Statistics anxiety: Nature, etiology, antecedents, effects, and treatments - a comprehensive review of the literature. Teaching in Higher Education, 8(2), 195-209.

[Online: http://dx.doi.org/10.1080/1356251032000052447]

Pajares, F., \& Miller, M. D. (1994). Role of self-efficacy and self-concept beliefs in mathematical problem solving: A path analysis. Journal of Educational Psychology, 86(2), 193-203.

[Online: http://dx.doi.org/10.1037/0022-0663.86.2.193]

Pintrich, P. R., \& Schunk, D. H. (2002). The role of goals and goal orientation. In P. R. Pintrich \& D. H. Schunk (Eds.), Motivation in education: Theory, research and application (2nd ed., pp. 190242). Englewood Cliffs, NJ: Simon \& Schuster.

Ramirez, C., Emmioğlu, E., \& Schau, C. (2010, August). Understanding students' attitudes toward statistics: New perspectives using an Expectancy-Value Model of motivation and the Survey of Attitudes Toward Statistics. Paper presented at Joint Statistical Meetings, Vancouver.

[Online: http://www.evaluationandstatistics.com/JSM2010EVM.pdf]

Roberts, D. M., \& Saxe, J. E. (1982). Validity of a statistics attitude survey: A follow-up study. Educational and Psychological Measurement, 42(3), 907-912.

[Online: http://dx.doi.org/10.1177/001316448204200326]

Ruggeri, K., Diaz, C., Kelley, K., \& Papousek, I. (2008, July). International study of statistics anxiety. Paper presented at the Third International Conference on the Teaching of Psychology, St. Petersburg, Russia.

[Online: http://ictp-2008.spb.ru/presentations/paper_session5/international_study_of statistical_anxiety.php]

Shechter, O. G., Durik, A. M., Miyamoto, Y., \& Harackiewicz, J. M. (2011). The role of utility value in achievement behaviour: The importance of culture. Personality and Social Psychology Bulletin, 37, 303-317.

[Online: http://dx.doi.org/10.1177/0146167210396380]

Schau, C. (1992). Survey of Attitudes Toward Statistics (SATS-28).

[Online: http://evaluationandstatistics.com/]

Schau, C. (2003a). Survey of Attitudes Toward Statistics (SATS-36).

[Online: http://evaluationandstatistics.com/]

Schau, C. (2003b, August). Students' attitudes: The "other" important outcome in statistics education. Paper presented at Joint Statistical Meetings, San Francisco, CA. [Online: http://www.statlit.org/pdf/2003SchauASA.pdf]

Schau, C., Stevens, J. J., Dauphinee, T. L., \& Del Vecchio, A. M. (1995). The development and validation of the Survey of Attitudes Toward Statistics. Educational and Psychological Measurement, 55(5), 868-875.

[Online: http://dx.doi.org/10.1177/0013164495055005022] 
Schutz, P. A., Drogosz, L. M., White, V. E., \& Distefano, C. (1998). Prior knowledge, attitude and strategy use in an introduction to statistics course. Learning and Individual Differences, 10(4), 291-308.

[Online: http://dx.doi.org/10.1016/S1041-6080\%2899\%2980124-1]

Sorge, C., \& Schau, C. (2002, April). Impact of engineering students' attitudes on achievement in statistics. Paper presented at the annual meeting of the American Educational Research Association, New Orleans.

[Online: http://evaluationandstatistics.com/AERA2002.pdf]

Tremblay, P. F., Gardner, R. C., \& Heipel, G. (2000). A model of the relationships among measures of affect, aptitude, and performance in introductory statistics. Canadian Journal of Behavioral Science, 32(1), 40-48.

[Online: http://dx.doi.org/10.1037/h0087099]

VanderStoep, S. W., \& Shaughnessy, J. J. (1997). Taking a course in research methods improves reasoning about real-life events. Teaching of Psychology, 24(2), 122-124.

[Online: http://dx.doi.org/10.1207/s15328023top2402_8]

Vanhoof, S., Kuppens, S., Sotos, A. E. C., Verschaffel, L., \& Onghena, P. (2011). Measuring statistics attitudes: Structure of the Survey of Attitudes Toward Statistics (SATS-36). Statistics Education Research Journal, 10(1), 35-51.

[Online: http://www.stat.auckland.ac.nz/ iase/serj/SERJ10\%281\%29 Vanhoof.pdf]

Wigfield, A. (1994). Expectancy-value theory of achievement motivation: A developmental perspective. Educational Psychology Review, 6(1), 49-78.

[Online: http://dx.doi.org/10.1007/BF02209024]

Wigfield, A., \& Cambria, J. (2010). Expectancy-value theory: Retrospective and prospective. In T. C. Urdan \& S. A. Karabenick (Eds.), The decade ahead: Theoretical perspectives on motivation and achievement (Advances in motivation and achievement, Vol. 16, pp. 35-70). Bingley, UK: Emerald Group Publishing Limited.

[Online: http://dx.doi.org/10.1108/S0749-7423\%282010\%29000016A005]

Wigfield, A., \& Eccles, J. S. (2000). Expectancy-value theory of achievement motivation. Contemporary Educational Psychology, 25(1), 68-81.

[Online: $\mathrm{http}: / / \mathrm{dx}$. doi.org/10.1006/ceps.1999.1015]

Wigfield, A., \& Eccles, J. S. (2002). The development of competence beliefs, expectancies for success, and achievement values from childhood through adolescence. In A. Wigfield \& J. S. Eccles (Eds), Development of achievement motivation (pp. 91-120). San Diego: Academic Press.

Wise, S. L. (1985). The development and validation of a scale measuring attitudes toward statistics. Educational and Psychological Measurement, 452, 401-405.

MICHELLE HOOD

School of Applied Psychology and Griffith Health Institute

Griffith University

Parklands Drive

Southport QLD 4222

Australia 